\title{
Structure Elucidation and Synthesis of Alkaloids Isolated from Fruits of Evodia rutaecarpa
}

\author{
Toshiya Kamikado, Shigeo MuraKoshi ${ }^{* 1, * 3}$ and Saburo Tamura ${ }^{* 2}$ \\ Research Laboratories, Agricultural Chemicals Division, Takeda Chemical \\ Industries, Ltd., Yodogawa-ku, Osaka *1Kanagawa Prefectural Institute \\ for Sericultural Science, Ebina-shi, Kanagawa *2 The Institute of \\ Physical and Chemical Research, Wako-shi, Saitama
}

Received January 27, 1978

\begin{abstract}
Five alkaloids were isolated from ripe fruits of Evodia rutaecarpa Ноок. f. et Tномs. Four of these were found to be indoloquinazoline type alkaloids: rutecarpine (I), evodiamine (II) and two new alkaloids, dihydrorutecarpine (IV) and its 14-formyl derivative (III). The remaining one was a new quinolone alkaloid, 1-methyl-2-nonyl-4(1H)-quinolone (V). The synthesis of II, III and IV was also achieved.
\end{abstract}

In the previous work to find insect growth inhibitors in Evodia rutaecarpa HooK $f$. et THOMs., we isolated three quinolone alkaloids from fresh leaves and young fruits of the plant. ${ }^{13}$ In continuation of the investigation we isolated from ripe fruits four indoloquinazoline alkaloids including two new compounds together with a new quinolone alkaloid. Further, the synthesis of the indoloquinazoline alkaloids was achieved. In this paper we wish to report the isolation, structure elucidation and synthesis of the alkaloids.

Ripe fruits of E. rutaecarpa were extracted with methanol. An ethyl acetate-soluble neutral fraction separated from the extract was subjected to silicic acid-celite column chromatography. The column was eluted successively with benzene, benzene-ethyl acetate and ethyl acetate. From the eluate with $5 \%$ ethyl acetate in benzene were isolated compounds I and II. The both compounds were identified as rutecarpine and evodiamine, which have been separated earlier from the same plant. ${ }^{2,3)}$ The eluate with $10 \%$ ethyl acetate in benzene was separated into ethyl acetate soluble and insoluble fractions. The latter fraction gave crystals, which were recrystallized from dimethylformamide-methanol to afford compound III, $\mathrm{mp} 280 \sim 281^{\circ} \mathrm{C}$. The ethyl

\footnotetext{
*3 Present address: Kanagawa Horticultural Experiment Station, Ninomiya, Kanagawa.
}

acetate soluble fraction was applied to preparative thin-layer chromatography (TLC) using benzene-ethyl acetate $(10: 3)$ to afford compound IV, $\mathrm{mp} 214 \sim 216^{\circ} \mathrm{C}$. The eluate with $40 \%$ ethyl acetate in benzene gave compound $\mathrm{V}, \mathrm{mp} 81 \sim 82^{\circ} \mathrm{C}$, together with dihydroevocarpine $^{1)}$ and 1-methyl-2-undecyl-4(1H)-quinolone. ${ }^{11}$

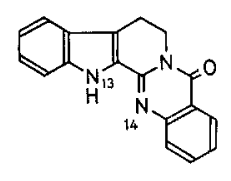

I

FIG. 1.

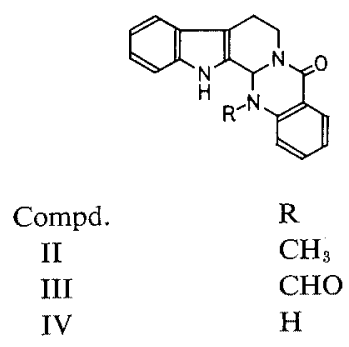

FIG. 2.

From the mass spectrum $\left(\mathrm{M}^{+} 317\right)$ and elemental analysis the molecular formula of compound III was assigned as $\mathrm{C}_{19} \mathrm{H}_{15} \mathrm{~N}_{3} \mathrm{O}_{2}$. The NMR spectrum showed no methyl protons but revealed methylene protons at $\delta$ 2.6 4.8 $(4 \mathrm{H}, \mathrm{m})$, aromatic protons at $\delta 6.8 \sim 8.0(8 \sim$ 
$9 \mathrm{H}, \mathrm{m})$, indole $\mathrm{NH}$ at $\delta 11.05(1 \mathrm{H}, \mathrm{s})$, and one proton at $\delta 9.10(\mathrm{~s})$. In the IR spectrum, two carbonyl bands were observed at 1695 and $1644 \mathrm{~cm}^{-1}$. Upon heating with $5 \% \mathrm{KOH}$ in ethanol, compound III afforded rutecarpine accompanying the loss of $\mathrm{CH}_{3} \mathrm{O}$. The presence of formyl group was suggested by a carbonyl band at $1695 \mathrm{~cm}^{-1}$ in the IR spectrum as well as by a signal at $\delta 9.10$ in the NMR spectrum. The pattern of the UV spectrum of III with characteristic absorptions at $291(\max , \log \varepsilon: 3.91)$ and 283 (shoulder, 3.93) $\mathrm{nm}$ was similar to that of evodiamine (II), rather than to that of rutecarpine (I). Therefore, the bond between 13b (C) and 14 (N) in III should be single. The formyl group was considered to be located on $14(\mathrm{~N})$ on the basis of chemical and spectral data and biogenetic view point. ${ }^{4}$ This assumption was supported by the mass spectrum: $m / e 288\left(\mathrm{M}^{+}\right.$ $\mathrm{CHO}$ ), 170 and 147 (arising from retro DielsAlder type fragmentation of the molecular ion, see Fig. 3). Thus, the structure of compound III was elucidated to be 14-formyldihydrorutecarpine.

Compound IV, $\mathrm{C}_{18} \mathrm{H}_{15} \mathrm{~N}_{3} \mathrm{O}$ (mass spectrum, $\mathrm{M}^{+} 289$ and elemental analysis), showed the UV spectrum similar to that of III. In the NMR spectrum, a signal at $\delta 6.06(1 \mathrm{H}, \mathrm{s})$ was ascribed to a proton of $13 \mathrm{~b}$ position. The IR spectrum revealed two NH bands at 3330 and $3280 \mathrm{~cm}^{-1}$ and a carbonyl band at $1633 \sim 1609$ $\mathrm{cm}^{-1}$. In addition, the presence of retro DielsAlder type fragment ions, $m / e 170$ and 119 , in the mass spectrum suggested that compound IV has dihydrorutecarpine structure.
Oxidation of IV with manganese dioxide afforded rutecarpine. Accordingly, the structure of compound IV was determined to be $13 \mathrm{~b}$, 14-dihydrorutecarpine (dihydrorutecarpine).

The molecular formula of compound $\mathrm{V}$ was determined as $\mathrm{C}_{19} \mathrm{H}_{27} \mathrm{NO}$ by the mass spectrum $\left(\mathrm{M}^{+}\right.$285) and elemental analysis. The compound showed IR, NMR and mass spectra quite similar to those of 2-alkyl-1-methyl$4(1 \mathrm{H})$-quinolones reported in the previous paper. ${ }^{1)}$ The mass spectrum revealed the base peak at $m / e 173\left(\mathrm{M}^{+}-\mathrm{C}_{8} \mathrm{H}_{15}\right)$ arising from McLafferty rearrangement of the molecular ion, together with fragment peaks with successive intervals of 14 mass units between $m / e 270\left(\mathrm{M}^{+}-\mathrm{CH}_{3}\right)$ and $186\left(\mathrm{M}^{+}-\mathrm{C}_{7} \mathrm{H}_{15}\right)$. Accordingly, the side chain in $\mathrm{V}$ was considered to be $n$-nonyl, and the structure of compound $\mathrm{V}$ must be 1-methyl-2-nonyl-4(1H)-quinolone.

Clauder et $a l .{ }^{5}$ already reported the synthesis of dihydrorutecarpine (IV) from $\mathrm{N}$-formyltriptamine acetal and anthranilic acid, but the melting point $\left(250 \sim 255^{\circ} \mathrm{C}\right.$, dec.) and the IR band $\left(\mathrm{NH}, 3250 ; \mathrm{CO}, 1660 \mathrm{~cm}^{-1}\right)$ of the product in the literature were inconsistent with those of the natural dihydrorutecarpine obtained here.

For the identification, we attempted the synthesis of IV according to Clauder's method, but neither IV nor the product reported in the literature were obtainable. Kametani et al. ${ }^{3)}$ prepared rutecarpine (I) in one step from 3,4dihydro- $\beta$-carboline and 3,2,1-benzoxathiazin-4(1H)-one 2-oxide (VI). Then, we treated isatoic anhydride, in place of VI, with 3,4dihydro- $\beta$-carboline in dry benzene-pyridine at

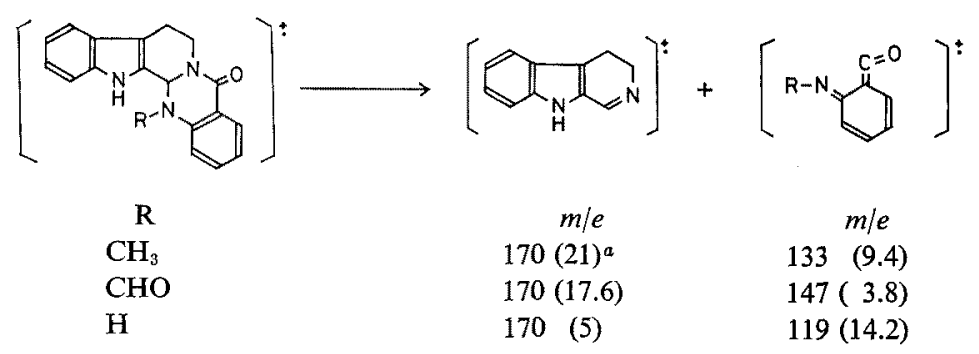

FIG. 3. Retro Diels-Alder Type Fragment Ions Observed in the Mass Spectra of Three Indoloquinazoline Alkaloids.

a Figures in parentheses represent relative intensities of the ions. 

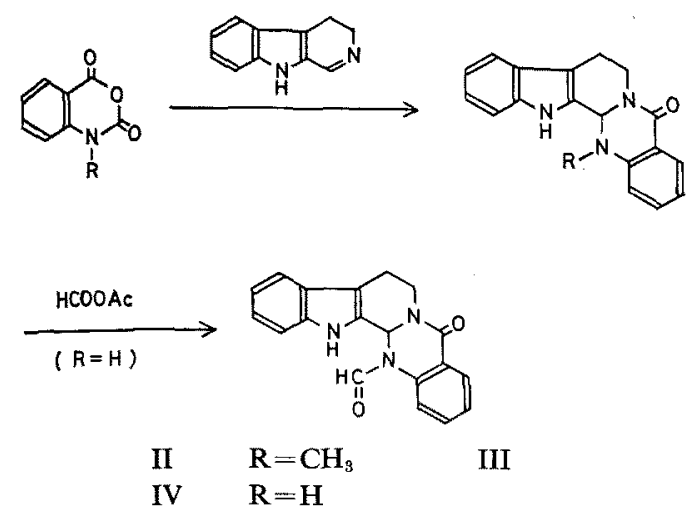

FIG. 4.

$60^{\circ} \mathrm{C}$ and successfully obtained IV in $71.5 \%$ yield. Oxidation of the product with manganese dioxide gave rutecarpine. The NMR and mass spectra of synthetic IV were identical with those of the natural product. However, the melting point $\left(227 \sim 230^{\circ} \mathrm{C}\right)$ of the synthetic sample was higher than that $\left(214 \sim 216^{\circ} \mathrm{C}\right)$ of the natural one. Further, the IR spectra $(\mathrm{KBr})$ of the both samples were inconsistent in some respects (Fig. 5). These might be due to the formation of racemic compound in the crystals of synthetic IV.

The above reaction was also applied to the synthesis of evodiamine (II). Treatment of 3,4-dihydro- $\beta$-carboline with $N$-methylisatoic anhydride at $55^{\circ} \mathrm{C}$ gave II in $66 \%$ yield. The physicochemical data of the product were identical with those of the natural sample.

Formylation of IV with acetic formic an- hydride in pyridine were unsuccessful. When the reaction was carried out in formic acid, however, 14-formyldihydrorutecarpine (III), mp $281 \sim 282^{\circ} \mathrm{C}$, was obtained in $79 \%$ yield. The NMR and mass spectra of the product were identical with those of the natural product, while some inconsistancy was observed in the IR spectra ( $\mathrm{KBr}$, see EXPERIMENTAL).

It has been reported that indoloquinazoline alkaloids are biosynthesized from tryptophan and anthranilic acid. ${ }^{4)}$ 14-Formyldihydrorutecarpine is supposed to be an oxidation product of evodiamine in this biogenetic system, and dihydrorutecarpine may be an intermediate product in the biosynthesis of rutecarpine.

The absolute configurations of the indoloquinazoline alkaloids in this paper remain to be elucidated.

Every alkaloid obtained here showed growthinhibitory effect on silkworm larvae by oral administration. Details of the biological activities will be reported elsewhere.

\section{EXPERIMENTAL}

All melting points are uncorrected. UV spectra were determined on a Hitachi EPS-3T Recording Spectrophotometer. IR spectra were recorded on a Hitachi EPI-G3 Grating Infrared Spectrophotometer. NMR spectra were measured with Varian $\mathrm{XL}-100$ and HA100 NMR Spectrometer. The data were obtained at $100 \mathrm{MHz}$ and indicated by $\delta$ values from tetramethylsilane as a standard. Mass spectra were recorded with a JMS-01SG Mass Spectrometer. Thin-layer chromatography (TLC) was conducted by use of Silica gel

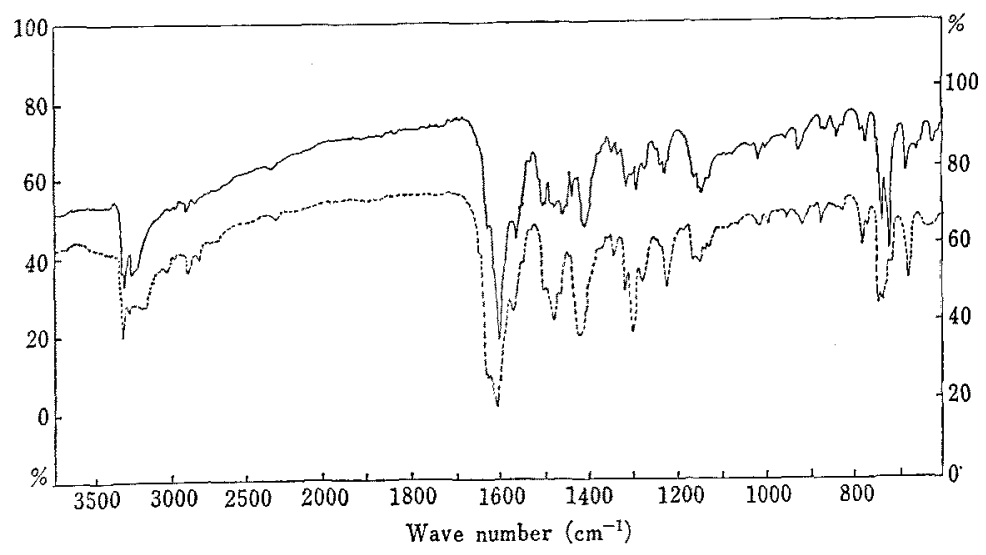

FIG. 5. IR Spectra of Dihydrorutecarpine (KBr).

-, natural product; ------, synthetic sample. 
$\mathrm{GF}_{254}$ Type 60 (Merck), and preparative TLC was carried out on plates of the same materials $(0.5 \mathrm{~mm}$ thickness). For reversed-phase TLC, Silica gel $G_{254}$ plates were immersed for $2 \mathrm{~min}$ in a solution of $5 \%$ silicone (Shimadzu, Silicone D.C. 200) in ether and the siliconized plates were used immediately after evaporation of the solvent. Spots on chromatograms were detected with a UV lamp and Dragendorff reagent. Column chromatography was performed by use of Silica gel 60 (Merck) and Celite 545 (Johns-Manville).

\section{Separation of neutral fraction}

Ripe fruits $(300 \mathrm{~g})$ of $E$. rutaecarpa were collected at Kyoto Herbal Garden of Takeda Chemical Industries, Ltd., early in December of 1975 . The fruits were extracted with two $1000 \mathrm{ml}$-portions of methanol in a blender, and the combined extracts were evaporated under reduced pressure. The residue was extracted with three $100 \mathrm{ml}$-portions of ethyl acetate at $\mathrm{pH} 3$. The combined extracts were shaken with two $80 \mathrm{ml}-$ portions of saturated aq. $\mathrm{NaHCO}_{3}$, dried over anhyd. $\mathrm{Na}_{2} \mathrm{SO}_{4}$ and filtered. The filtrate was evaporated under reduced pressure to give a neutral fraction as a dark-green oil $(4.9 \mathrm{~g})$.

\section{Isolation of alkaloids}

The neutral fraction $(4.9 \mathrm{~g}$ ) was dissolved in $50 \mathrm{ml}$ of acetone and was shaken with $5 \mathrm{~g}$ of celite. After evaporation of the solvent under reduced pressure, the resulting powder was applied onto a column $(43 \times 200 \mathrm{~mm})$ packed with silica gel-celite $(90 \mathrm{~g}+30 \mathrm{~g})$. The column was successively eluted with $1000 \mathrm{ml}$ each of benzene, benzene-ethyl acetate $(9.5: 0.5 ; 9: 1 ; 8: 2$; $6: 4)$ and ethyl acetate. Each eluate was evaporated under reduced pressure to give oils. Yields were as follows: $842,827,908,891,628,253 \mathrm{mg}$ in the order of elution.

Isolation of rutecarpine (I) and evodiamine (II). The oil $(40 \mathrm{mg})$ from the eluate with $5 \%$ ethyl acetate in benzene was subjected to preparative TLC by the use of silicic acid and benzene-ethyl acetate $(4: 1)$. The crude crystals $(9 \mathrm{mg})$ obtained from a zone at $R f 0.58$ were recrystallized from benzene-ethyl acetate to give compound I (rutecarpine) as pale yellow needles, mp $263 \sim 264^{\circ} \mathrm{C}$ (Lit. ${ }^{2)} 256^{\circ} \mathrm{C}$, Lit. ${ }^{3)} 259^{\circ} \mathrm{C}$ ). MS m/e: $287\left(\mathrm{M}^{+}\right) . \quad$ IR $\nu_{\mathrm{max}}^{\mathrm{KBr}} \mathrm{cm}^{-1}: 3345,1653,1600,1475$, $1408,1335,1237,772,764,738,731$. NMR $\delta^{\mathrm{d}_{6}-\mathrm{DMSO}}$ M $3.18(2 \mathrm{H}, \mathrm{t}, J=7 \mathrm{~Hz}), 4.45(2 \mathrm{H}, \mathrm{t}, J=7 \mathrm{~Hz}), 7.0 \sim 7.9$ $(7 \mathrm{H}, \mathrm{m}), 8.18(1 \mathrm{H}, \mathrm{d}, J=8 \mathrm{~Hz}), 11.85(1 \mathrm{H}, \mathrm{br})$.

The crude crystals $(25 \mathrm{mg})$ obtained from a zone at Rf 0.48 were recrystallized from benzene-ethyl acetate to give compound II (evodiamine) as colorless leaflets, mp $268 \sim 272^{\circ} \mathrm{C}$ (Lit. ${ }^{2)} 270 \sim 272^{\circ} \mathrm{C}$ ). MS m/e: 303 $\left.\mathrm{M}^{+}\right), 170,169,133,134$. IR $\nu_{\mathrm{m} \mathrm{ax}}^{\mathrm{K} \mathrm{Rr}} \mathrm{cm}^{-1}: 3225,1640$,

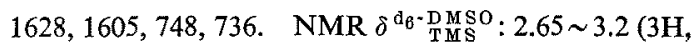
m), $2.90(3 \mathrm{H}, \mathrm{s}), 4.67(1 \mathrm{H}, \mathrm{d} \cdot \mathrm{t}, J=10 \mathrm{~Hz}, 3 \mathrm{~Hz}), 6.12$
$(1 \mathrm{H}, \mathrm{s}), 6.9 \sim 7.65(7 \mathrm{H}, \mathrm{m}), 7.83(1 \mathrm{H}, \mathrm{d} \cdot \mathrm{d}, J=9 \mathrm{~Hz}$, $2 \mathrm{~Hz}), 11.05(1 \mathrm{H}, \mathrm{s})$.

Isolation of compounds III and IV. The oil $(900 \mathrm{mg})$ from the eluate with $10 \%$ ethyl acetate in benzene was dissolved in $20 \mathrm{ml}$ of ethyl acetate and insoluble solids $(350 \mathrm{mg})$ were collected by filtration. The solids $(300 \mathrm{mg})$ were recrystallized twice from methanoldimethylformamide to give compound III (109 $\mathrm{mg}$ ) as colorless needles, mp $280 \sim 281^{\circ} \mathrm{C}$. MS $m / e: 317\left(\mathrm{M}^{+}\right)$, 288, 287 (base peak), 170, 169, 148, 147. Anal. Found: C, 71.95; H, 4.71; N, 13.12. Caled. for $\mathrm{C}_{10} \mathrm{H}_{18} \mathrm{~N}_{8} \mathrm{O}_{2}$ : C, $71.98 ; \mathrm{H}, 4.77 ; \mathrm{N}, 13.26 \% .[\alpha]_{\mathrm{D}}^{28}+260^{\circ}(c=0.535$, DMF). UV $\lambda_{\mathrm{max}}^{\mathrm{MeOH}} \mathrm{nm}(\log \varepsilon): 291$ (3.91), 283 (sh, 3.98). IR $\nu_{\max }^{\mathrm{KBr}} \mathrm{cm}^{-1}: 3265,1695,1644,1606,1491$, 1385, 1288, 1240, 1230, 765 (sh), 758, 741, 707, 692, 640. NMR $\delta{ }^{\mathrm{d}_{6}} \cdot{ }_{\mathrm{MMSO}}^{\mathrm{DMSO}}: 2.6 \sim 3.7(3 \mathrm{H}, \mathrm{m}), 4.72(1 \mathrm{H}, \mathrm{d} \cdot \mathrm{d}$, $J=12.5 \mathrm{~Hz}, 5 \mathrm{~Hz}), 6.8 \sim 7.7(8 \mathrm{H}, \mathrm{m}), 7.92(1 \mathrm{H}, \mathrm{d}$, $J=8 \mathrm{~Hz}), 9.1(1 \mathrm{H}, \mathrm{s}), 11.05(1 \mathrm{H}, \mathrm{br} \mathrm{s})$.

The ethyl acetate soluble fraction was evaporated under reduced pressure to give an oil $(547 \mathrm{mg})$, which was subjected to preparative TLC by the use of silicic acid and benzene-ethyl acetate $(10: 3)$. The crystals (79 mg) obtained from a zone at $R f 0.46$ were rechromatographed with the same system and then recrystallized from ethyl acetate to afford compound IV $(26 \mathrm{mg})$ as pale yellow prisms, $\mathrm{mp} 214 \sim 216^{\circ} \mathrm{C}$. MS m/e: 289 $\left(\mathrm{M}^{+}\right), 288$ (base peak), 287, 170, 169, 120, 119. Anal. Found: $\mathrm{C}, 74.39 ; \mathrm{H}, 5.03 ; \mathrm{N}, 13.92$. Calcd. for $\mathrm{C}_{13} \mathrm{H}_{1 \overline{5}} \mathrm{~N}_{3} \mathrm{O}: \mathrm{C}, 74.71 ; \mathrm{H}, 5.22 ; \mathrm{N}, 14.35 \% .[\alpha]_{D}^{28}$ $-564^{\circ}(c=0.355, \mathrm{DMF}) . \quad \mathrm{UV} \lambda_{\max }^{\mathrm{MeOH}} \mathrm{nm}(\log \varepsilon): 290$ (3.91), 281 (4.03). IR $\nu_{\max }^{\mathrm{KBR}} \mathrm{cm}^{-1}: 3330,3280,1633$, 1618 (sh), 1609, 1425, 760 (sh), 750, 735 (see Fig. 5). NMR $\delta^{\mathrm{d}_{8}-\mathrm{DMSO}}: 2.65 \sim 3.4(4 \mathrm{H}, \mathrm{m}), 4.83(1 \mathrm{H}, \mathrm{d} \cdot \mathrm{t}$, $J=13 \mathrm{~Hz}, 3 \mathrm{~Hz}), 6.06(1 \mathrm{H}, \mathrm{s}), 6.7 \sim 7.6(7 \mathrm{H}, \mathrm{m}), 7.80$ $(1 \mathrm{H}, \mathrm{d} \cdot \mathrm{d}, J=8 \mathrm{~Hz}, 2 \mathrm{~Hz}), 10.9(1 \mathrm{H}, \mathrm{br} \mathrm{s})$.

Isolation of compound $V$. The yellowish green oil $(160 \mathrm{mg})$ from the eluate with $40 \%$ ethyl acetate in benzene was dissolved in $20 \mathrm{ml}$ of dichloromethane. The solution was added with $m$-chloroperbenzoic acid $(130 \mathrm{mg})$ and stirred for $4 \mathrm{hr}$ at room temperature. The reaction mixture was washed with aq. $\mathrm{NaHCO}_{3}$, dried over anhyd. $\mathrm{Na}_{2} \mathrm{SO}_{4}$ and evaporated under reduced pressure to give an oil $(150 \mathrm{mg})$. The oil was applied to preparative TLC using silicic acid and ethyl acetate. A zone at $R f 0.38$ was extracted with ethyl acetate and evaporated to give a quinolone alkaloid mixture as a colorless oil. The mixture $(56 \mathrm{mg})$ was applied to preparative reversed-phase TLC using siliconized silicic acid plates and acetonitrile-acetic acid-water $(7: 3: 5)$. The silica gel powder collected from a zone at $R f 0.68$ was washed with ether and extracted with ethyl acetate. The extract was washed with $10 \%$ aq. $\mathrm{NaHCO}_{3}$, dried over anhyd. $\mathrm{Na}_{2} \mathrm{SO}_{4}$ and 
evaporated to afford crude crystals of compound $\mathrm{V}$ $(9.7 \mathrm{mg})$, which were recrystallized from ethyl acetateether to give colorless leaflets melting at $81 \sim 82^{\circ} \mathrm{C}$.

Dihydroevocarpine (4 mg) and 1-methyl-2-undecyl-4 (1H)-quinolone $(19 \mathrm{mg})$ were also obtained from zones at $R f 0.40$ and $R f 0.54$, respectively.

\section{Alkaline cleavage of compound III}

To a solution of $0.25 \mathrm{~g}$ of potassium hydroxide in $5 \mathrm{ml}$ of $95 \%$ ethanol was added $13 \mathrm{mg}$ of compound III. The mixture was heated under reflux for $6 \mathrm{hr}$. After cooling, the separated crystals were collected and dried to give $4.2 \mathrm{mg}$ of needles, $\mathrm{mp} 262 \sim 264^{\circ} \mathrm{C}$. Concentration of the filtrate gave further $5 \mathrm{mg}$ of crystals (mp 262 264 ${ }^{\circ} \mathrm{C}$ ). The both specimens were found to be identical with compound I (rutecarpine) through mixed melting point determination and comparisons of IR spectra.

\section{Dxidation of compound IV}

To a solution of $6.5 \mathrm{mg}$ of compound IV in $2 \mathrm{ml}$ of acetone was added $25 \mathrm{mg}$ of manganese dioxide. The mixture was stirred for $6 \mathrm{hr}$ at room temperature and allowed to stand overnight. After filtration of the mixture, the filtrate was concentrated to dryness. The residue was recrystallized from ethyl acetate-acetone to give $4 \mathrm{mg}$ of colorless needles, $\mathrm{mp} 264^{\circ} \mathrm{C}$. The product was found to be identical with compound I by mixing melting point and spectral measurement.

\section{Synthesis of dihydrorutecarpine (IV)}

To a mixture of 3,4-dihydro- $\beta$-carboline $(173 \mathrm{mg})^{6)}$ and isatoic anhydride $(163 \mathrm{mg})$ in dry benzene was added dry pyridine $(0.5 \mathrm{ml})$, and the mixture was warmed to $60^{\circ} \mathrm{C}$. The crystals of isatoic anhydride dissolved with evolution of carbon dioxide and then new crystals were deposited. After stirring for $30 \mathrm{~min}$ at $60^{\circ} \mathrm{C}$, the reaction mixture was cooled to $10^{\circ} \mathrm{C}$ and filtered to give the crystals $(186 \mathrm{mg}$ ) of $\mathrm{IV}$, which were recrystallized from ethyl acetate-acetone to afford colorless needles melting at $227 \sim 230^{\circ} \mathrm{C}$. Anal. Found: C, 74.49; $\mathrm{H}, 5.04 ; \mathrm{N}, 14.33$. Calcd. for $\mathrm{C}_{18} \mathrm{H}_{15} \mathrm{~N}_{3} \mathrm{O}$ : C, $74.71 ; \mathrm{H}, 5.22 ; \mathrm{N}, 14.35 \%$. IR (see Fig. 5). The NMR and mass spectra of the product were identical with those of the natural product.

\section{Synthesis of evodiamine (II)}

A mixture of 3,4-dihydro- $\beta$-carboline $(61 \mathrm{mg}), \mathrm{N}$ methylisatoic anhydride $(62 \mathrm{mg})$ and pyridine $(1 \mathrm{ml})$ in dry benzene $(4 \mathrm{ml})$ was stirred for $2 \mathrm{hr}$ at $55^{\circ} \mathrm{C}$ and filtered. On cooling, crystals appeared in the filtrate. The crystals were collected and washed with benzene to give II $(57.1 \mathrm{mg})$. Concentration of the mother liquor followed by recrystallization from dimethylformamideacetone afforded further $12.5 \mathrm{mg}$ of II. Mp 269 $271^{\circ} \mathrm{C}$. Anal. Found: C, 74.95; H, 5.61; N, 13.62. Calcd. for $\mathrm{C}_{19} \mathrm{H}_{17} \mathrm{~N}_{3} \mathrm{O} ; \mathrm{C}, 75.22 ; \mathrm{H}, 5.65 ; \mathrm{N}, 13.85 \%$. The IR, NMR and mass spectra of the product were identical with those of the natural product. The mixture melting point with the natural product showed no depression.

\section{Synthesis of 14-formyldihydrorutecarpine (III)}

A mixture of acetic anhydride $(0.2 \mathrm{ml})$ and formic acid $(0.3 \mathrm{ml})$ was warmed for $10 \mathrm{~min}$ at $55^{\circ} \mathrm{C}$ and cooled to room temperature. Dihydrorutecarpine $(15 \mathrm{mg})$ was added to the mixture and stirred for $2 \mathrm{hr}$. The solution was concentrated to dryness under reduced pressure and the residue was washed with a small amount of cold methanol to give $13 \mathrm{mg}$ of III. Mp $281 \sim 282^{\circ} \mathrm{C}$. IR $\nu_{\max }^{\mathrm{KBr}} \mathrm{cm}^{-1}: 3320,1688,1640,1605$, $1491,1375,1283,1225$ (sh), 769, 758, 742, 700, 660, 630. The NMR and mass spectra of the product were identical with those of the natural product. The mixture melting point with the natural product showed no depression.

Acknowledgement. The authors wish to express our thanks to Mr. T. Takahashi of the Pharmacognotic Research Laboratories of Takeda Chemical Industries, Ltd. for providing the plant materials. We also thank Dr. K. Ono of Agricultural Chemicals Division of the Company and Mr. K. Morii of Kanagawa Prefectural Institute for Sericultural Science for their cooperation.

\section{REFERENCES}

1) T. Kamikado, C.-F. Chang, S. Murakoshi, A. Sakurai and S. Tamura, Agric. Biol. Chem., 40, 605 (1976).

2) T. Nakasato, S. Asada and K. Marui, Yakugaku Zasshi, 82, 619 (1961).

3) T. Kametani T. Higa and K. Fukumoto, Heterocycles, 4, 23 (1976).

4) M. Yamazaki, A. Ikuta, T. Mori and T. Kawana, Tetrahedron Lett., 1967, 3317.

5) O. Clauder and K. Horváth-Dóra, Acta Chim. (Budapest), 72, 221 (1972).

6) Y. Kanaoka, E. Sato and Y. Ban, Chim. Pharm. Bull., 15, 101 (1967). 